\title{
Properties of Light MMCs Modified with Cordierite Synthesized from Fly Ash
}

\author{
Piotr Długosz, Angelika Rączka, Adrian Kopeć, Rudolf Krzyżak, Paweł Darłak, and Marek Hebda
}

\author{
(Submitted November 1, 2015; in revised form March 31, 2016; published online May 5, 2016)
}

\begin{abstract}
This paper presents novel opportunities for management of fly ash by synthesizing the material into cordierite ceramics and using it as a reinforcing phase for light metal alloys. Metal matrix composites (based on magnesium alloy and aluminum alloy) were produced by squeeze casting. The magnesium matrix composites with a suitably selected reinforcing phase content $(2 \mathrm{wt} . \%)$ exhibited much better strength properties than the unmodified alloy (AM60). It was also demonstrated that the wettability (or the lack thereof) in the metal-ceramic system is critical to successful production of the composites based on the AK7 alloy with cordierite. Light alloy matrix composites reinforced with cordierite ceramics particles are innovative materials that combine high strength with low weight, which may be a key factor of merit for numerous applications of the composite in various branches of industries.
\end{abstract}

Keywords AK7 alloy, AM60 magnesium alloy, fly ash, metal matrix composites, squeeze casting, wettability

\section{Introduction}

Composites are a wide group of materials with valuable physical and chemical properties, and present in many fields of industry and science. The design scope for composites is usually focused on several criteria, such as capacity to significantly improve mechanical properties, or capacity to extend the application range, e.g., high-temperature applications, increased vibration dampening performance, increased abrasion resistance, and many more. Whether the designed criteria are met or not is largely conditioned by numerous factors, including composite ingredients' properties, sizes, shapes, alignment, volume ratio, and matrix reinforcement distribution (Ref 1). Light alloys, e.g., magnesium or aluminum alloys, have become increasingly popular as matrices for MMCs. A specific characteristic attributed to light alloys (aside from their relatively low density) is its favorable strength $\left(R_{\mathrm{m}}\right)$ to density ratio (or elastic modulus $(E)$ to density ratio). The materials can carry similar static and dynamic loads as iron alloys, albeit having a much lower weight (Ref 2). The development of lightweight structural materials is among the greatest challenges due to, e.g., economic and environmental concerns. Light metal matrix composites allow for significant energy efficiency. Moreover, the materials of this kind contribute to minimum consumption of strategic natural resources (Ref 3). Light metal matrix composites allow for cost effectiveness in operation of transport vehicles, e.g., by reducing fuel consumption while increasing mobility. The promise of these benefits have actually triggered an increased interest in composite

Piotr Długosz, Rudolf Krzyżak, and Pawel Darlak, Foundry Research Institute, Zakopiańska 73, 30-418 Kraków, Poland; and Angelika Rączka, Adrian Kopeć, and Marek Hebda, Institute of Materials Engineering, Cracow University of Technology, Warszawska 24, 31-155 Kraków, Poland. Contact e-mail: mhebda@pk.edu.pl. materials in most applications such as the automotive, aerospace, and marine industries, just to name a few (Ref 1, 4-10).

A novel approach to the design of metal matrix composites is the application of a reinforcement material derived by synthesis of cordierite $\left(\mathrm{Mg}_{2} \mathrm{Al}_{4} \mathrm{Si}_{5} \mathrm{O}_{18}\right)$ from fly ash. This synthesis has been performed according to procedure described in (Ref 11). The production of cordierite ceramics from fly ash is inexpensive, while building the ceramic fitting that will act as a pre-mold for saturation of the matrix with the liquid matrix requires no special equipment, foaming agents, binders or hot processing. Cordierite is a natural mineral commercially available in powders, granulates or finished molded pieces. The relatively high purchase pricing substantiates the profitability of synthetic cordierite from fly ash. The cordierite manufacturing process is environmentally friendly, and the resulting fittings see universal use. The manufacturing process is simple and cordierite processing can be quickly adapted for mass production demands without any investment in additional ceramic synthesis machinery (Ref 11). Currently, many methods of fly ash management exist (Ref 12-14). Use of cordierite ceramics synthesized from fly ash in light MMC casting is aligned with the schedule for reduction of the environmental impact of conventional power engineering (e.g. by liquidation of landfills and dumps disposal) and, given the increasing consumption of hard coal, has been becoming increasingly important. Light alloy matrix composites reinforced with cordierite particles are innovative materials that combine high strength with low weight, which may be a key factor to numerous applications of the composite in various industries. Furthermore, production of such materials allows for environmental protection and waste management opportunities.

This paper shows the experimental results from an analysis of the manufacturability of light metal matrix alloys (from AM60 and AK7 alloys) with cheap and easily available reinforcement (cordierite ceramics) synthesized from fly ash. The paper presents the x-ray diffraction (XRD) analysis, the changes in their microstructure as well as the strength properties of the produced materials. Phenomena related to the wettability of AK7 alloy which determine the MMC manufacturability are also discussed. 


\section{Material and Methods}

Commonly used casting alloys, the AK7 aluminum alloy and the AM60 magnesium alloys were selected as the metal matrix for the composites. The chemical composition of the alloys is shown in Table 1. The reinforcing material was cordierite ceramics $\left(\mathrm{Mg}_{2} \mathrm{Al}_{4} \mathrm{Si}_{5} \mathrm{O}_{18}\right)$ manufactured by synthesis of fly ash. The chemical composition is shown in Table 2 . Cordierite ceramics was introduced into the matrix at 2 and 4 wt.\% as a powder produced by grinding in a high-power ball mill at $1800 \mathrm{rpm}$ for $2 \mathrm{~h}$. The MMCs were manufactured at (ca. $50{ }^{\circ} \mathrm{C}$ ) above the matrix melting point in the vortex process. The samples were squeeze cast into a dia. $200-\mathrm{mm}$ cylindrical mold at the press force of 160 tons. The reference material selected for the experiments were MMC samples without cordierite, i.e. made of the base alloys (see Table 1) with the identical process.

The microsections were visually examined under a Nikon Eclipse ME600 microscope. The chemical composition was analyzed using Jeol 6510LV SEM with an XRF 500 Energy Dispersive $\mathrm{x}$-ray spectroscopy (EDS) module. The phase identification was performed by an $\mathrm{x}$-ray diffraction apparatus PANalytical Empyrean (anode: $\mathrm{Cu}$ (copper); counting time $200 \mathrm{~s}$; step of measurement: $0.026^{\circ}$ ). The static tensile and compressive strength tests were carried out on an MTS Criterion 43 strength-testing machine. The tensile strength test followed the protocol of PN-EN ISO 6892-1:2010 on dumbbell samples with the tension rate of $0.5 \mathrm{~mm} / \mathrm{min}$. The compressive strength was tested on cylindrical samples of $5 \mathrm{~mm}$ in diameter and $10 \mathrm{~mm}$ in height. The traverse feed was $0.5 \mathrm{~mm} / \mathrm{min}$. Wettability was examined by the flat drop test with contact heating (Ref 15). The materials were cleaned in an ultrasound washer isopropanol bath prior to the measurements. Next, a drop of the AK7 alloy was laid flat on a cordierite sample and heated at a rate of $10^{\circ} \mathrm{C} / \mathrm{min}$ to $900{ }^{\circ} \mathrm{C}$, held there for $30 \mathrm{~min}$, and then cooled at $10{ }^{\circ} \mathrm{C} / \mathrm{min}$. The measurements were carried out in vacuum. The test subject was recorded in a digital camera during the experiment (with a framerate of $1 \mathrm{fps}$ until the melt-through, followed by $10 \mathrm{pfs}$ until frozen), and the videos served to assess the contact angle $(\theta)$. The produced images were digitally processed in the ASTRA software package, developed by CNR-Instituto per I'Energetici e le Interfasi - U.T. di Genova, Italy, to calculate the contact angle.

\section{Results and Discussion}

Figures 1 and 2 show the microsections of the AM60 base alloy and the MMC with $4 \mathrm{wt} \%$ of cordierite ceramics, respectively. The AM60 base alloy seemed to feature two phases (i) the matrix, and (ii) relatively numerous precipitates (indicated as phase 1 in the Fig. 1 and 2), characterized by oblong and/or irregular forms. The distribution of precipitates is very regular, with local joints established between them. It is most likely that the precipitates are crystallized in the areas between the grain boundaries. The MMC structures, both with 2 and 4 wt.\% of cordierite ceramics, reveal one additional phase (indicated as phase 2 in the Fig. 2). It is manifest as very fine (needle-like) precipitates that cross one another at the right angle very often. The quantity of the phase increases in direct proportion with the amount of the reinforcement (cordierite ceramics) introduced to the MMC.

However, these variations are not witnessed in the AK7 MMC (Fig. 3). The microstructures of the examined samples were always approximate to the base alloy, irrespective of the amount of reinforcement. Two distinct phases were found therein: (i) the matrix and (ii) a large number of uniformly distributed lamellar/needle precipitates. The lack of microstructural modification may be indicative of failure in their manufacture.

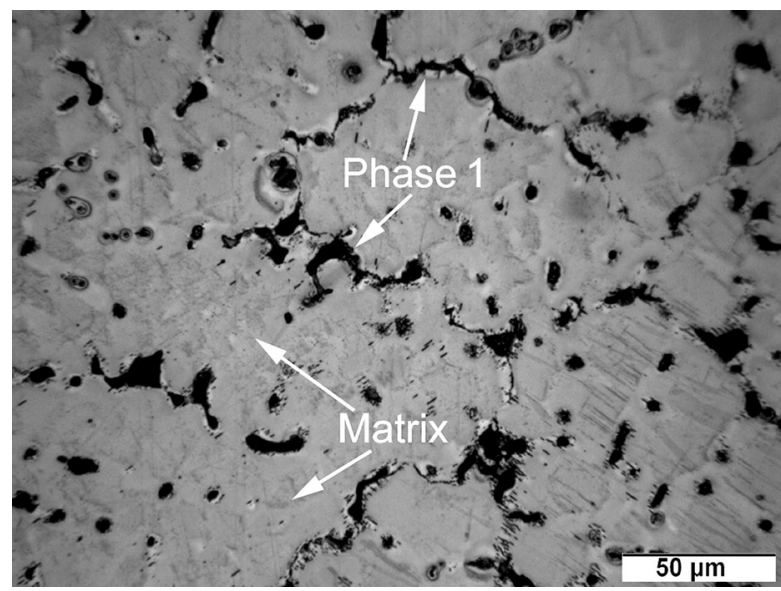

Fig. 1 Microstructure of AM60 alloy

Table 1 Chemical compositions of the AK7 aluminum alloy and the AM60 magnesium alloy as the metal matrix for the experimentally manufactured composites

\begin{tabular}{lllllllll}
\hline & \multicolumn{7}{c}{ Chemical composition ,wt.\% } \\
\cline { 2 - 8 } Designation & $\mathbf{S i}$ & Cu & Mg & Mn & Fe & Ti & Zn & Al \\
\hline AK7 & 7.0 & Max 0.05 & 0.35 & Max 0.1 & Max 0.19 & 0.16 & Max 0.07 & Balance \\
AM60 & Max 0.5 & Max 0.35 & Balance & $0.13-0.6$ & $\ldots$ & $\ldots$ & 0.22 & $5.5-6.5$ \\
\hline
\end{tabular}

Table 2 Chemical compositions of the cordierite ceramics as the reinforcement for the experimentally manufactured MMC

\begin{tabular}{lcccccrrr}
\hline & \multicolumn{7}{c}{ Chemical composition, wt.\% } \\
\cline { 2 - 7 } Designation & $\mathbf{S i O}_{\mathbf{2}}$ & $\mathbf{A l}_{\mathbf{2}} \mathbf{O}_{\mathbf{3}}$ & $\mathbf{F e O}_{\mathbf{3}}$ & $\mathbf{M g O}$ & $\mathbf{C a O}$ & $\mathbf{N a}_{\mathbf{2}} \mathbf{O}$ & $\mathbf{H}_{\mathbf{2}} \mathbf{O}$ \\
\hline Cordierite ceramics & $45-51$ & $32-35$ & $2-12$ & $3-35$ & Max 3 & Max 3 & Max 3 \\
\hline
\end{tabular}




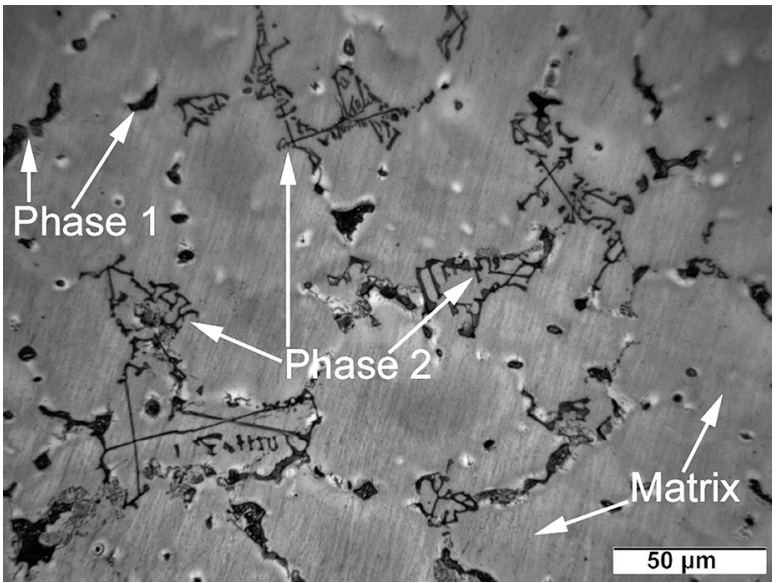

Fig. 2 AM60 MMC microstructure with 4 wt.\% of cordierite ceramics

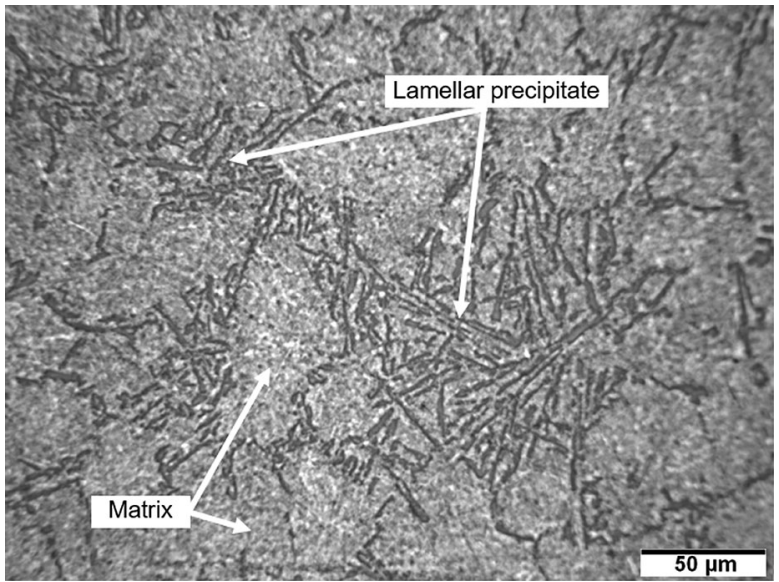

Fig. 3 AK7 MMC microstructure with 4 wt.\% of cordierite ceramics

The AM60 MMC as well as AK7 MMC, each with the addition of 4 wt.\% of cordierite, were subjected to an XRD analysis to explicitly identify the chemical composition of its phases (Fig. 4 and 5, respectively). The main phase in AM60 alloy was $\mathrm{Mg}_{0.976} \mathrm{Al}_{0.024}$ phase (indicated in Fig. 1 and 2 as a matrix). Moreover, the discontinuous precipitation along the grain boundaries, described as phase 1 in Fig. 1 and 2, was $\mathrm{Al}_{12} \mathrm{Mg}_{17}$ phase. According to XRD patterns (Fig. 4), $\mathrm{Mg}_{2} \mathrm{Si}$ phase was only found in the alloys with cordierite ceramics' addition. This phase was indicated as phase 2 in the Fig. 2. With the increasing cordierite ceramics' additions, the content of $\mathrm{Mg}_{2} \mathrm{Si}$ phase increases gradually. Furthermore, XRD spectra show some remnants of the ceramics as $\mathrm{MgO}$ phase, while the AK7 MMC mainly contains $\mathrm{Al}$ matrix and $\mathrm{Al}_{3.21} \mathrm{Si}_{0.47}$ phase (lamellar precipitates) in matrix (Fig. 5).

EDS microanalysis of representative randomly selected areas of the AM60 MMC alloy with 4 wt.\% of cordierite ceramics is shown in Fig. 6. The results of the analysis of the specific microstructural areas are listed in Table 3. Figure 7 shows the variations in aluminum- and silicon-content levels in the chemical compositional microanalysis in the area marked with the red line in Fig. 6. Based on the quantitative EDS analysis, it was found where each intersection of the

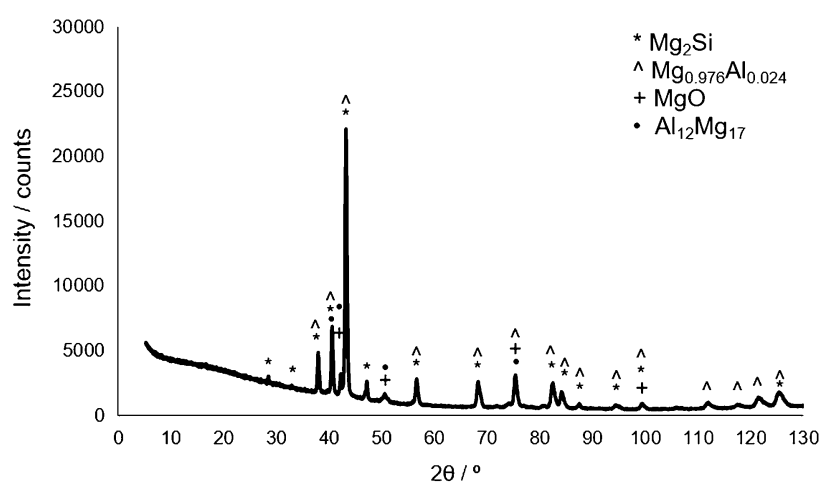

Fig. 4 XRD patterns of AM60 alloy with 4 wt.\% of cordierite ceramics

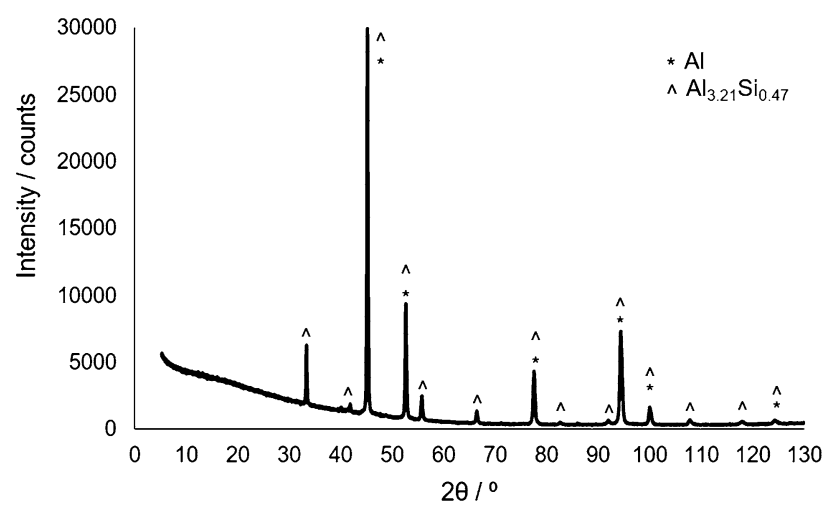

Fig. 5 XRD patterns of AK7 alloy with 4 wt.\% of cordierite ceramics

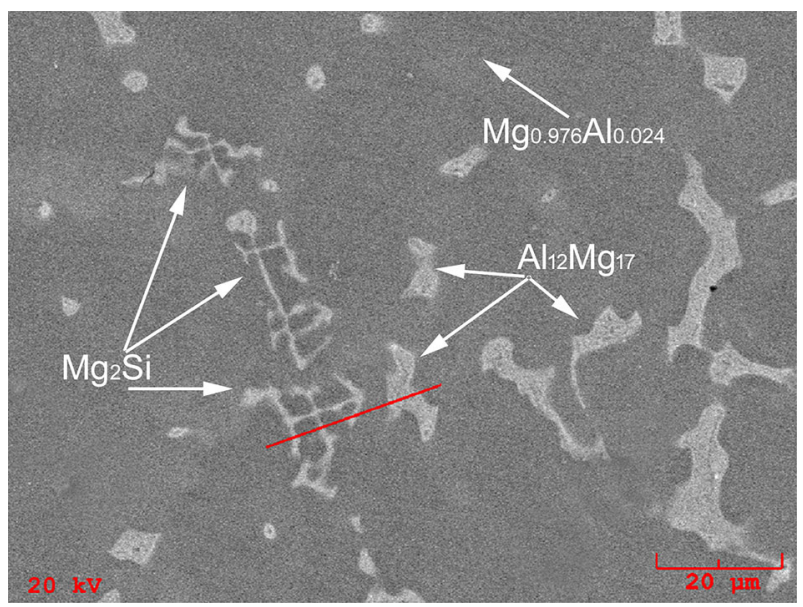

Fig. 6 SEM-imaged microstructures with the areas of the chemical compositional microanalysis (point and linear) for the AM60 MMC with 4 wt. $\%$ of cordierite ceramics

scan lines in $\mathrm{Mg}_{2} \mathrm{Si}$-phase measurements caused strong peaks of the silicon-level readings (Fig. 7). The aluminum readings would increase only when $\mathrm{Al}_{12} \mathrm{Mg}_{17}$ phase analysis began (Fig. 6 and 7). The results explicitly confirm that an MMC was manufactured, since the silicon detected in the samples (and in the discovered amounts) could only originate from the 
Table 3 Chemical compositional microanalysis results for individual phases (shown in Fig. 2) of the AM60 MMC with $4 \mathrm{wt} . \%$ of cordierite ceramics

\begin{tabular}{lccr}
\hline & \multicolumn{2}{c}{ Measurement area } \\
\cline { 2 - 4 } Element, wt.\% & Matrix & Phase 1 & Phase 2 \\
\hline $\mathrm{Mg}$ & 100 & $71.62 \pm 6.72$ & $91.20 \pm 7.47$ \\
$\mathrm{Al}$ & $\ldots$ & $28.38 \pm 2.55$ & $4.20 \pm 1.01$ \\
$\mathrm{Si}$ & $\ldots$ & $\ldots$ & $4.60 \pm 1.15$ \\
\hline
\end{tabular}

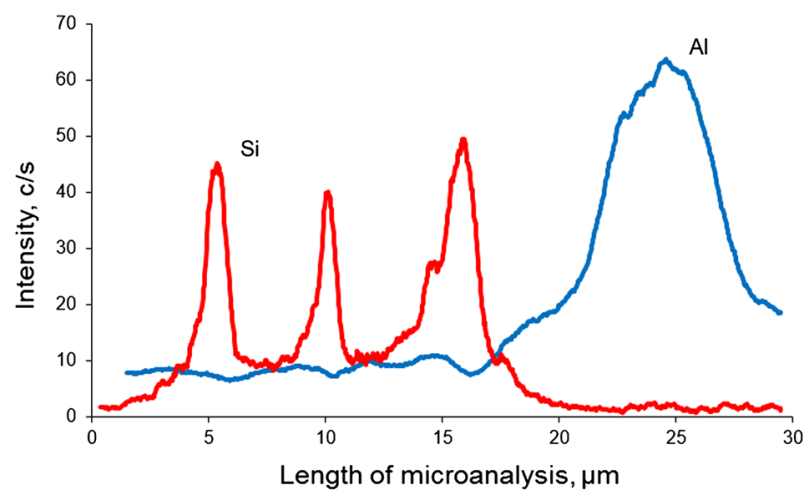

Fig. 7 Variations of aluminum (a) and silicon (b) intensities in the AM60 MMC with 4 wt.\% of cordierite ceramics recorded by linear chemical compositional microanalysis at the position marked with the red line in Fig. 6

Table 4 Chemical compositional microanalysis results for individual phases (shown in Fig. 3) of the AK7 MMC with $4 \mathrm{wt} . \%$ of cordierite ceramics

\begin{tabular}{lrr}
\hline & \multicolumn{2}{c}{ Measurement area } \\
\cline { 2 - 3 } Element, wt.\% & Matrix & Precipitates \\
\hline $\mathrm{Al}$ & 100 & $74.63 \pm 6.22$ \\
$\mathrm{Si}$ & $\ldots$ & $16.49 \pm 2.14$ \\
$\mathrm{Mg}$ & $\cdots$ & $8.88 \pm 2.41$ \\
\hline
\end{tabular}

reinforcing phase, namely cordierite ceramics. Bearing in mind the low amount of silicon in the AM60 alloy, one can suppose that the Si diffuses from the ceramics. Recalling the discussion on the same elements $(\mathrm{Mg}, \mathrm{Al}, \mathrm{Si})$ in the ceramics and in the alloy, one can suppose the dissemination (and solution) of the elements by the alloy.

The interfacial reaction between the reinforcing phases and the alloy could be conceivable:

$$
4 \mathrm{Mg}+2 \mathrm{SiO}_{2}=\mathrm{Mg}_{2} \mathrm{Si}+2 \mathrm{MgO}
$$

or

$$
2 \mathrm{Mg}+\mathrm{SiO}_{2}=\mathrm{Si}+2 \mathrm{MgO}
$$

The addition of silica and the dissolution of the elements seem to be of paramount importance for investigated composites.

The AK7 MMCs with cordierite were also subjected to the chemical compositional microanalysis (Table 4). Its results reveal that the alloy matrix is made of aluminum, whereas the

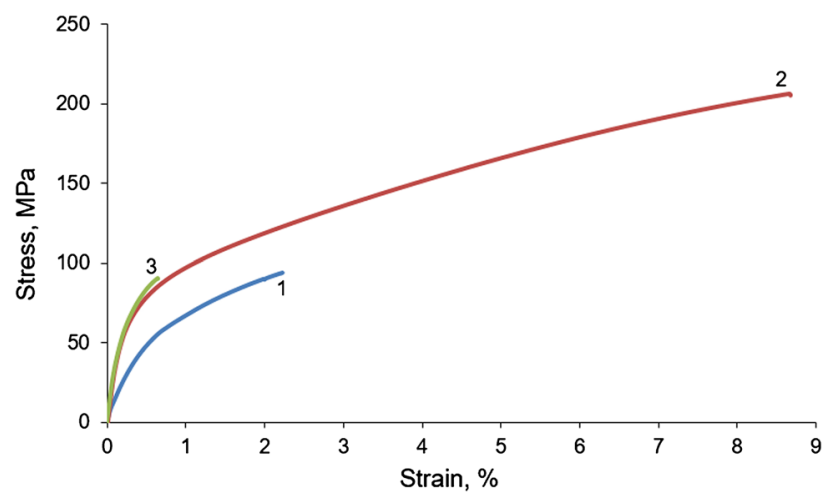

Fig. 8 Stress-strain curves of 1-AM60 alloy, 2-AM60 with 2 wt. $\%$ of cordierite ceramics, 3-AM60 with 4 wt.\% of cordierite ceramics

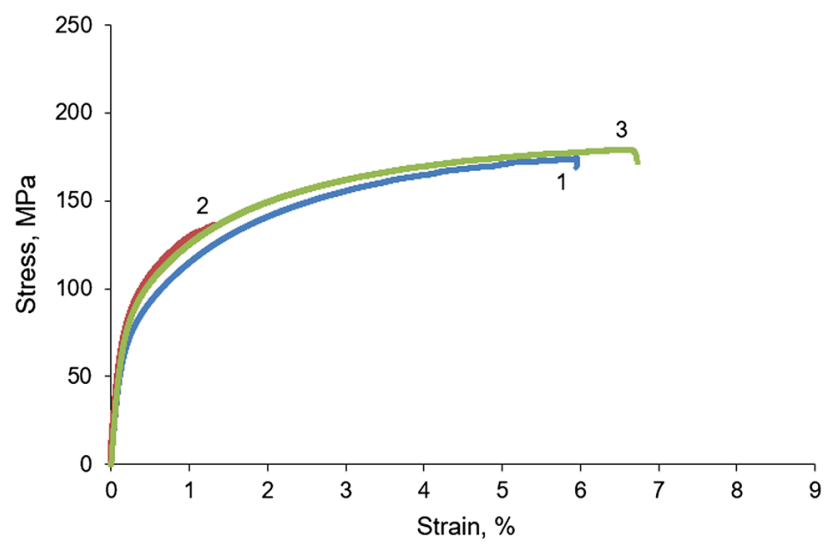

Fig. 9 Stress-strain curves of $1-\mathrm{AK} 7$ alloy, 2-AK7 with 2 wt.\% of cordierite ceramics, 3 - AK7 with 4 wt. $\%$ of cordierite ceramics

needle-like precipitates shown in Fig. 3 are a mixture of aluminum and silicon (possibly with low levels of magnesium). In general, composition of the MMC can be approximated to the $\mathrm{Al}-\mathrm{Mg}_{2} \mathrm{Si}-\mathrm{Si}$ eutectic. Note that the $\mathrm{AK} 7$ base alloy contains ca. $7 \%$ of silicon; hence, the measurements disallow any conclusion whether cordierite was introduced or not.

Figures 8 and 9 as well as Table 5 show the strength properties of all the tested materials. The results demonstrate that a 2 wt.\% addition of cordierite ceramics to AM60 alloy resulted in a nearly twofold increase in tensile strength (relative to the unmodified alloy). Moreover, the elongation of the MMCs grew by three times. The $4 \mathrm{wt} \%$ addition of the reinforcement resulted in worse MMC performance (which 
Table 5 Strength properties of the experimentally manufactured materials from the static tension test

\begin{tabular}{|c|c|c|c|c|}
\hline Material & $R_{\mathrm{m}}, \mathrm{MPa}$ & $R_{0.2}, \mathrm{MPa}$ & $E, \mathbf{G P a}$ & $A, \%$ \\
\hline AM60 & $97 \pm 2.5$ & $54 \pm 7.5$ & $27 \pm 7.5$ & $2.2 \pm 0.1$ \\
\hline $\mathrm{AM} 60 \pm 2 \mathrm{wt} . \%$ of cordierite ceramics & $181 \pm 25.5$ & $64 \pm 8.5$ & $37 \pm 4.5$ & $7.3 \pm 1.4$ \\
\hline $\mathrm{AM} 60 \pm 4$ wt. $\%$ of cordierite ceramics & $93 \pm 1.5$ & $79 \pm 1.5$ & $38 \pm 1.5$ & $0.7 \pm 0.1$ \\
\hline AK7 & $174.4 \pm 0.6$ & $77.6 \pm 15.3$ & $47.0 \pm 1.7$ & $5.3 \pm 0.9$ \\
\hline $\mathrm{AK} 7 \pm 2$ wt. $\%$ of cordierite ceramics & $142.3 \pm 8.8$ & $89.9 \pm 15.7$ & $41.2 \pm 8.8$ & $1.8 \pm 0.6$ \\
\hline $\mathrm{AK} 7 \pm 4$ wt. $\%$ of cordierite ceramics & $160.7 \pm 25.9$ & $85.5 \pm 8.6$ & $46.3 \pm 2.2$ & $4.0 \pm 3.9$ \\
\hline
\end{tabular}

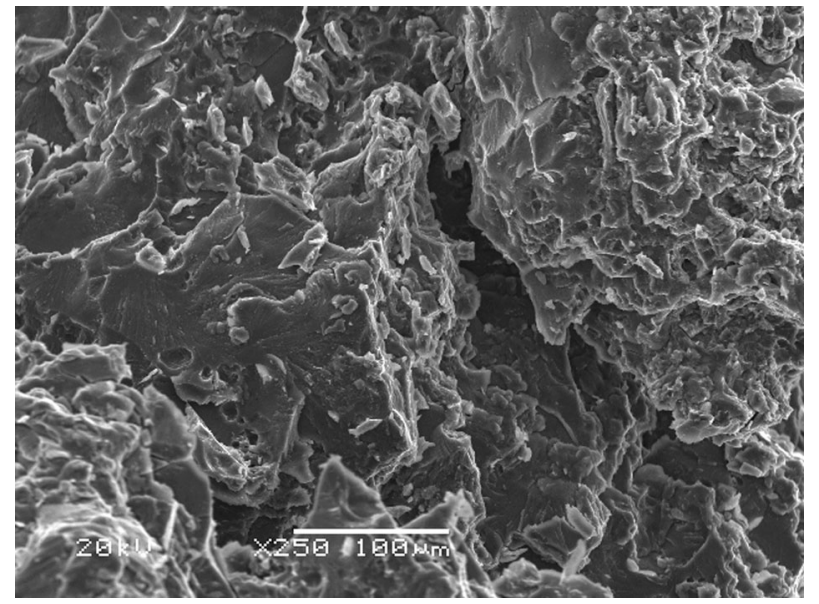

Fig. 10 Fractographs of post-tensile fractures recorded for the AM60 alloy

were approximate to or sometimes worse than in the AM60 alloy).

The strength properties of the aluminum MMCs are nearly identical to (or sometimes much worse than) the results for the AK7 alloy. Yet again the results confirm that cordierite addition as a reinforcement failed in the aluminum alloy.

The described strength relationships are fully represented in Fig. 10 and 11 that shows the fractographs of the tensile tested sample fractures of the AM60 alloy and the AM60 MMCs with 2 wt.\% of cordierite, respectively. All the fractures are quasicleavage type in nature. There are facets of quasi-cleavage observed during plastic deformation, resulting in the characteristic cleavage ridges. Increased shares in plastic deformation (in the MMCs with 2 wt.\% of cordierite) are evident, e.g., by the pronounced waviness of the fracture, the increased highlight of the cleavage ridge edges, or the larger number of pits that are typical of ductile cracking.

The AM60 MMCs were also subjected to compressive strength testing. The results are shown in Table 6. Again, the highest strength properties were found in the MMC with $2 \mathrm{wt} \%$ of cordierite. Moreover, all the tested samples suffered slip failure by shearing. The extreme tangential stress was at $45^{\circ}$ relative to the sample axis.

The produced test results show that the density of input materials of MMCs is not a key factor to guarantee homogeneous introduction of reinforcement to the alloy matrix. Despite the approximate densities of AK7 (ca. $2.7 \mathrm{~g} / \mathrm{cm}^{3}$ ) and cordierite ceramics (ca. $2.6 \mathrm{~g} / \mathrm{cm}^{3}$ ), the attempt to bind the materials had failed. Even with the large difference between the densities of AM60 (ca. $1.8 \mathrm{~g} / \mathrm{cm}^{3}$ ) and cordierite, the MMC was produced without any problems. The results show that densities of the

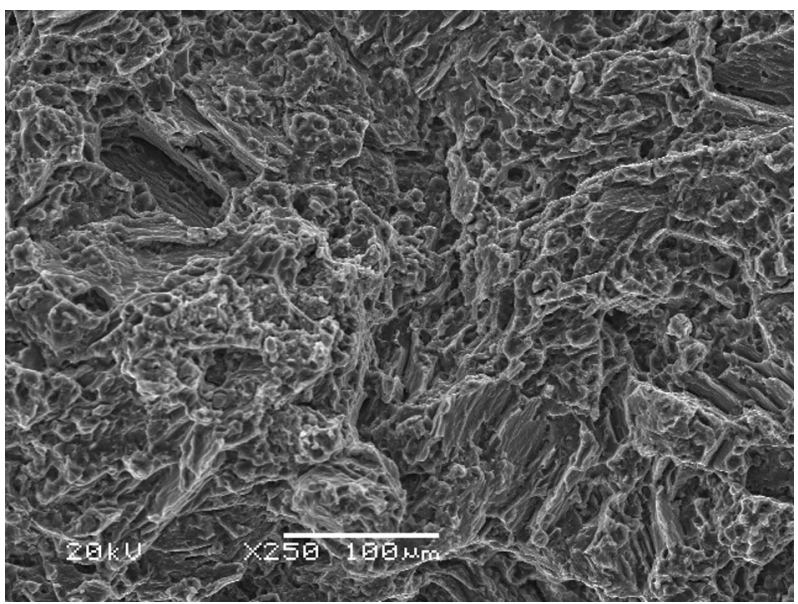

Fig. 11 Fractographs of post-tensile fractures recorded for the AM60 MMCs with 2 wt.\% of cordierite ceramics

Table 6 The results of compressive strength testing

\begin{tabular}{llc}
\hline Material & $\boldsymbol{R}_{\mathbf{m}}, \mathbf{M P a}$ & $\boldsymbol{A}, \boldsymbol{\%}$ \\
\hline AM60 & $371 \pm 3.5$ & $26.86 \pm 0.82$ \\
AM60 $\pm 2 \%$ of cordierite ceramics & $393 \pm 5.5$ & $26.09 \pm 1.16$ \\
AM60 \pm 4\% of cordierite ceramics & $339 \pm 19.0$ & $20.24 \pm 1.97$ \\
\hline
\end{tabular}

MMCs with addition of cordierite ceramics have not changed significantly relative to the base alloys.

The most probable key effect that guarantees the feasibility of reinforcing the metal matrix is wettability (or the lack thereof) of the reinforcement surface. Wettability analyses were conducted on the AK7-cordierite system to verify this assumption. The measured mean value (of six measurements) of the contact angle $(\theta)$ was $149.4^{\circ} \pm 3.1^{\circ}$. The results explicitly prove zero wettability of the AK7-cordierite system.

\section{Conclusions}

The experiments and tests have proven an innovative light metal matrix composite was produced, which has a great potential for various applications. It has also been proven that the AM60 magnesium alloy can be modified by homogeneous introduction of cordierite as its reinforcement. The bonding of the reinforcing phase with the magnesium alloy has been demonstrated to be good. With the proper amounts of reinforcement, the MMCs exhibit better properties than AM60. The highest increment in strength properties (for 
tension and compression) was observed in samples with $2 \mathrm{wt} . \%$ of cordierite. Higher ratios of reinforcement in the magnesium alloy reduce the strength properties.

The attempt to manufacture an AK7 aluminum-based MMC with cordierite has failed. The root cause of the outcome is poor wettability between the aluminum alloy and cordierite.

Moreover, the production of cordierite from fly ash, followed by its application as a reinforcing phase in light alloys, opens new opportunities for fly ash management, which is extremely important due to environmental and cost-effectiveness concerns.

\section{Acknowledgments}

This research was supported by the Project POIG No. 01.01.02$00-015 / 09$

\section{Open Access}

This article is distributed under the terms of the Creative Commons Attribution 4.0 International License (http://creativecommons.org/ licenses/by/4.0/), which permits unrestricted use, distribution, and reproduction in any medium, provided you give appropriate credit to the original author(s) and the source, provide a link to the Creative Commons license, and indicate if changes were made.

\section{References}

1. T.S. Srivatsan, C. Godbole, M. Paramsothy, and M. Gupta, The Role of Aluminium Oxide Particulate Reinforcement on Cyclic Fatigue and Final Fracture Behaviour of a Novel Magnesium Alloy, Mater. Sci. Eng. A, 2012, 532, p 196-211

2. Z. Górny and J. Sobczak, Nowoczesne tworzywa odlewnicze na bazie metali nieżelaznych, ZA-PIS, Kraków, 2005
3. A.J. Knowles, X. Jiang, M. Galano, and F. Audebert, Microstructure and Mechanical Properties of 6061 Al Alloy Based Composites with SiC Nanoparticles, J. Alloys Compd., 2014, 615, p 401-405

4. M. Paramsothy, X.N. Tan, J. Chan, R. Kwok, and M. Gupta, $\mathrm{Al}_{2} \mathrm{O}_{3}$ Nanoparticle Addition to Concentrated Magnesium Alloy AZ81: Enhanced Ductility, J. Alloys Compd., 2012, 545, p 12-18

5. H. Yong and R. Li, Effect of Particulate Reinforcement on Wear Behavior of Magnesium Matrix Composites, Trans. Nonferrous Met. Soc. China, 2012, 22, p 2659-2664

6. B. Anasori, N. Caspi, and M.W. Barsoum, Fabrication and Mechanical Properties of Pressureless Melt Infiltrated Magnesium Alloy Composites Reinforced with $\mathrm{TiC}$ and $\mathrm{Ti}_{2} \mathrm{AlC}$ Particles, Mater. Sci. Eng., A, 2014, 618, p 511-522

7. P. Rodgrigo, M. Campo, B. Torres, M.D. Escalera, E. Otero, and J. Rams, Microstructure and Wear Resistance of Al-SiC Composites Coatings on ZE41 Magnesium Alloy, Appl. Surf. Sci., 2009, 255, p 9174-9181

8. N.N. Lu, X.J. Wang, L.L. Meng, C. Ding, W.Q. Liu, H.L. Shi, X.S. Hu, and $\mathrm{K}$. Wu, Electromagnetic Interference Shielding Effectiveness of Magnesium Alloy-Fly Ash Composites, J. Alloys Compd., 2015, 650, p 871-877

9. P. Yu, L.C. Zhang, W.Y. Zhang, J. Dasa, K.B. Kima, and J. Eckert, Interfacial Reaction During the Fabrication of $\mathrm{Ni}_{60} \mathrm{Nb}_{40}$ Metallic Glass Particles-Reinforced Al Based MMCs, Mater. Sci. Eng. A, 2007, 444, p 206-213

10. H. Attar, M. Bonisch, M. Calin, L.-C. Zhang, S. Scudino, and J. Eckert, Selective Laser Melting of In Situ Titanium-Titanium Boride Composites: Processing, Microstructure and Mechanical Properties, Acta Mater, 2014, 76, p 13-22

11. P. Darłak, P. Długosz, and R. Krzyżak Zaawansowane materiały kompozytowe na bazie metali lekkich typu MAGFA i ALFA zbrojone popiołami lotnymi. Instytut Odlewnictwa, Kraków 2012

12. M. Ahmaruzzaman, A Review on the Utilization of Fly Ash, Prog. Energy Combust. Sci., 2010, 36, p 327-363

13. A. Grela, M. Hebda, M. Łach, and J. Mikuła, Thermal Behavior and Physical Characteristics of Synthetic Zeolite from CFB-coal Fly Ash, Microporous Mesoporous Mater, 2016, 220, p 155-162

14. N. Koshya and D.N. Singhb, Fly Ash Zeolites for Water Treatment Applications, J. Environ. Chem. Eng., 2016, 4, p 1460-1472

15. N. Sobczak, R. Nowak, W. Radziwill, J. Budzioch, and A. Glenz, Experimental Complex for Investigations of High Temperature Capillarity Phenomena, Mater. Sci. Eng. A, 2008, 495, p 43-49 